\title{
Chapter 2 \\ Identities of the First and Second Generation: The Role of Ethnicity
}

Having set the scene and introduced the main research questions in Chap. 1, the focus now moves on to identity, which is one of the main topics analysed in this book. Following the established literature, this chapter privileges analysis of the role of ethnicity in identity construction, but concludes that, for Albanians abroad, ethnicity in the primordial sense is not intrinsic to their identification processes. This chapter, and the three that follow, starts with a theoretical and conceptual section. In this case major developments are examined in the field of identity and ethnicity, pointing to the privileged status that ethnic identity has had in the study of migrants' and their descendants' identities. A historical introduction to Albanian identity identifies key moments that have defined the country's socio-cultural and political life. These have had repercussions for the starting point, the course and the 'outcome' of migration and identification of Albanian migrants and their children.

The empirical sections that follow are based on a thematic and comparative analysis across the three sites (London, Thessaloniki and Florence) and the three main groups: the first-generation migrants (parents), the second-generation teenagers, and teachers and key informants. The chapter examines the identities of the first generation, then analyses migrant and parental identity, and perceptions and understandings of gender and religious identity, concluding with the role of ethnicity in identity processes.

The third part of the chapter focuses on the identities of the children of migrants. The most prominent dimensions emerging from the data are teenager identity and perceptions of gender - and their role in identity processes - and religious identity. Once again, the role of primordial ethnic identity was downplayed. The chapter ends by drawing some conclusions on identity and the role of ethnicity.

\subsection{Identity and Ethnicity}

The literature on identity is characterized by various strands that are based on different epistemological and disciplinary approaches working at different levels. Indeed, one could not agree more with Gilroy (1996, pp. 224-225) who stylishly points 
to 'the passage into vogue' of identity and the 'academic mess' that surrounds the concept. One of the most confusing and analytically problematic approaches has been the 'soft' constructivist version, which posits that identity is multiple, fluid and always changing, which raises questions about its operationability and usefulness as a research construct. Brubaker and Cooper (2000) in their explicit 'attack' acknowledge the importance of the developmental approach in establishing the term and at the same time 'blame' Erikson (1968) for the start of a saga of confusing terms and models that made identity an ambiguous analytical concept. They instead propose the use of three clusters of terms: identification and categorization; self-understanding and social location; and commonality, connectedness and groupness. This reorganization of the identity literature highlights the growing emphasis on the processes and agents that do the identifying, the cognitive awareness and the multiple forms and degrees of commonality and connectedness discussed under various types of collective identities. Relating identity to a shared culture and perceived common origin has been the way ethnic identity has been differentiated from other social identities (Barth 1969; Jenkins 1997; Levine 1999; Vermeulen and Govers 1994).

Wimmer (2008) notes that academic discourse on the conceptualization of ethnicity has evolved around two dichotomous terms: 'primordialism', based on the assumption that ethnic membership is acquired through birth and thus represents a 'given' characteristic of the social world; and 'instrumentalism', which posits that individuals choose between various identities according to self-interest. Nowadays, this dichotomy has been blurred and the two terms are no longer seen as mutually exclusive. Viewing the dichotomy through a cognitive lens, Brubaker et al. (2004) argue that the real difference between the primordial and the situational stance is that the former emphasizes the tendency of participants to naturalize real or imputed human differences in the ways groups are conceived, while the situational approach can explain how ethnicity takes relevance in particular contexts and everyday interactions.

The development of ethnicity from the primordial stance to the cognitive approach has been long and fragmented. It is important to note here the definition of ethnic groups by Max Weber (Roth and Wittich 1976, p. 389):

\footnotetext{
[W]e shall call 'ethnic groups' those human beings that entertain a subjective belief in their common descent because of similarities of physical type or of customs or both, or because of memories of colonization and migration; thus belief must be important for the propagation of group formation; conversely it doesn't matter whether or not an objective blood relationship exists (italics added).
}

A crucial moment was the introduction into this debate of the concept of boundaries by Barth (1969), who considered ethnicity a product of a social process, attributing thus a more active role to individuals' and groups' engagement in redefining their ethnicity, by seeing ethnic identity as defined by the combination of the view one has for oneself and the views of others about one's ethnic identity. Others have followed a similar line. For instance, Alba (2005, p. 22) maintains that ethnicity 'is a distinction that individuals make in their everyday lives that shapes their actions and mental orientations towards others; and it is typically embedded in a variety of social and cultural differences between groups that give an ethnic boundary concrete 
significance'. Jenkins (1997, p. 165) delineates the post-Barthian anthropological model of ethnicity based on four propositions:

- ethnicity is about cultural differentiation (bearing in mind that identity is always a dialectic between similarity and difference);

- ethnicity is concerned with culture, or shared meaning, but it is also rooted in and is the outcome of social interaction;

- ethnicity is no more fixed than the culture of which it is a component or the situations in which it is produced and reproduced;

- ethnicity is both collective and individual, externalized in social interaction and internalized in personal self-identification.

Jenkins (2004) furthermore points to the contrast between individual and collective (ethnic) identities by maintaining that the individual identity emphasizes difference whereas the latter, similarity. By considering identity 'a practical accomplishment, a process', Jenkins $(2004$, p. 23 ) maintains that both individual and collective identities use a unified model of the dialectical interplay of processes of internal and external definition, with time and space being central to both these processes.

As signalled above, ethnicity is built on two major constructs: identity and culture (Nagel 1994). Ethnic identification, however, is not a 'flat' and uniform process across contexts and groups. Jenkins (1997) maintains that culture is taken for granted until the moment when identity is problematized along the interaction across the boundaries. Barth (1969, p. 14) recognized that the features that are proclaimed as distinct are not always objectively selected, but consist of those that the main actors regard as significant. The salience of ethnic categories can vary in different sociocultural systems; they may be 'inactive' or may pervade social life - in general or selectively in limited sectors of activity.

This view is furthermore elaborated by authors who relate ethnic identity and its performance to structure. While acknowledging these theoretical assumptions and the role of agency in identification processes, Nagel (1994, p. 155) maintains that 'the chosen ethnic identity is determined by the individual's perception of its meaning to different audiences, its salience in different social contexts, and its utility in different settings'. She further notes that ethnicity is both the product of actions undertaken by ethnic groups as they shape and reshape their self-definition and culture, and the 'outcome' of external social, economic and political processes and actors that shape and reshape ethnic categories and definitions. This view partly reflects the 'situational' stance on ethnic identity, which holds that ethnic identity is unstable over time and lifespan, with different settings 'activating' different aspects of one's possible group identities.

But what are the factors and actors that influence identity formation, and how do they combine in affecting the way that individuals and groups identify? Until recently, academic work on racial and ethnic identities has emphasized Barth's relational perspective and has considered these identities as the result of a process of self-definition, as well as of the construction of symbolic boundaries and assignment of collective identities by others (Lamont and Molnar 2002). However, most of the post-Barthian literature has overlooked the importance of external definition 
and social categorization and has mostly analysed ethnicity based on internal definition and group identification. Neither Barth nor the members of the Manchester School who developed the situational approach have paid sufficient attention to the external constraints that condition ethnic identification. The main working concepts extensively used in the study of ethnic identity, such as boundaries and choices, have proved to be useful to analyse the already established ethnic categories, but they do not explain how some ethnic categories are developed and engaged in social action (Levine 1999). This has been ordinarily associated with a conceptualization of social relationships as egalitarian and conflict-free, based on equitable negotiations (Jenkins 1997).

External categorization is, however, seen as framing and conditioning the internal malleable construction of identity at an individual level, and as a means used by political entrepreneurs to affect collective identification and modify collective action (Glick Schiller 2012b). Barth (1994) proposed a multiple-level approach, which entails a combination of the interpersonal interactions at the micro level, the processes that create collectivities at a meso level, and the role of state at the macro level.

Increasingly processes of identification are associated with issues of power. Barth (1994, p. 16), in his review of academic work on ethnic boundaries, maintains that the process of the construction of a boundary is a joint work shared between members of both contrasting groups, "though they are probably differently empowered in their ability to impose and transform the relevant idioms'. This empowerment is related to the salience of ethnicity in local settings as a result of differentiation, which results in ethnicity becoming an integral part of an individual's point of view of selfhood starting in early primary socialization. External categorization, however, features as an important factor in shaping ethnicity and the element through which power differentiations are expressed and materialized (Sökefeld 2001).

This view is taken up by Wimmer and Glick Schiller (2002), who furthermore emphasize that the anthropology of ethnic groups within modernizing or industrial nation-states tended to describe these as culturally different from the 'majority' population because of their varying historical origin, including their history of migration, rather than to see these differences as a consequence of the politicization of ethnicity in the context of nation-state building itself. The "politicization of ethnicity' was a central part of the nation-state project to define all those populations thought not to represent the 'national culture' as racially and culturally different, which contributed to efforts to build unity and identity (Glick Schiller 2012b). ${ }^{1}$ A newer conceptualization of ethnicity that followed maintains that ethnic boundaries are the outcome of the classificatory struggles and negotiations between actors situated in a social field and the behaviour and strategies of these actors are determined by three characteristics of a field: the institutional order, distribution of power and political networks (Wimmer 2008, p. 970).

However, Levine (1999, p. 168) maintains that too much emphasis has been put on forces of personal development and calls for more attention to be dedicated to the interaction between the mind, society and culture as main factors influencing

${ }^{1}$ As we saw in Chap. 1, this was certainly the case in Italy and Greece. 
the engagement of ethnic categories. Levine's view is part of the cognitive strand in studies of ethnicity, which criticizes the tendency towards 'groupism' in conceptualizing ethnic groups, taking them as the ubiquitous and elementary constituents of social life. Rather, this movement concentrates on 'group-making' through activities of classification, categorization and identification and considers groups as collective cultural representations (Brubaker and Cooper 2000, p. 45).

The cognitive approach, with its emphasis on cultural representations and the involvement of the mind in the elaboration of ethnic categories, gained even more credit with the introduction of an interactional model of identity formation by Todd (2005, p. 433). She gave full recognition to power relations and resource distribution as two important variables in explaining identity change. However, she notes:

\footnotetext{
If we posit a slowly changing 'cultural sub-stratum' that may underlie more radical category change, we need a different model of how identity-categories function. We need to recognize not just the complex and varying meanings of these categories and their lack of fixed or foundational status, but also their social 'embeddedness' and their personal 'anchorage', which allow change or stasis to occur out of phase with other variables, and to affect them in turn (ibid.).
}

The new model associated the process of identity formation and change with intentionality expressed in the incorporation of new elements of meaning and value while rearranging the old, or a combination of social practices in a new way, which leads to the production of different meanings. Todd (2005) maintains that the social constraints and the cognitive schemas rooted in early infancy are thought to condition this process, while calling for identity and culture to return into the models attempting to explain socio-cultural transformation.

On the other hand, wider social and cultural institutions and principles of social differentiation are thought to be strongly related to ethnic identity. Firstly, ethnicity is considered one of many sources of identification, overlapping with some important others, among which social class and gender feature strongly (Banton 2008). Anthias and Yuval-Davis (1992) call not only for a distinction to be drawn between notions of ethnic identity and ethnicity, since the latter refers to a practical term expressing mobilization on the basis of ethnic ideas, but also for consideration of ethnicity's intersections with class and gender, as other prime social divisions. Furthermore, this overlapping is seen to have implications for the process of external categorization. Broader principles of social differentiation impact on the ability of certain actors to categorize others, especially on the basis of relations of power and authority (Jenkins 1997).

This is why the concept of boundaries is back to the fore in studies of identities in various disciplines, emphasizing the need to look at the intersections of multiple identities. Interestingly, the idea of boundaries related to socio-cultural differences within ethnic groups dates back to the 1960s, with Gordon (1964, p. 234) defining an ethnic group as 'a large subsociety, criss-crossed by social class, and containing its own primary groups of families, cliques and associations - its own network of organizations and institutions'. However, as Çă̆lar (1997) maintains, in migration studies, ethnic identities (national or religious) are treated as the most basic identities that people possess, to the exclusion of other forms of identification, with ethnicity treated as the naturalized marker of an immutable cultural differ- 
ence. Recent studies on ethnic and racial boundaries are increasingly focusing on the construction of collective identities and are attempting to elaborate models that link cognitive and cultural aspects with the social processes underlying ethno-racial boundary-making (Pachucki et al. 2007).

The context-dependency of the nature of ethnic and racial boundaries is further supported by Alba (2005). He maintains that the process of defining the boundaries between immigrants and natives depends both on features of the social and institutional spheres of the host societies and on the characteristics and histories of the immigrant groups themselves. More importantly, Alba (2005) proposes the concept of 'boundary' as useful in conducting cross-country comparative research in ethnic and racial studies - which of course this study does.

The concept of boundaries, however, falls short in explaining the meaning, the content and the purposes that ethnic meanings serve. Nagel (1994, p. 162) points out that ethnic boundaries help us to understand who we are, but do not explain what we are, or, as she puts it, what fills 'Barth's vessel' (see also Anthias and Yuval-Davis 1992, p. 4). Here the concept of culture, seen itself as fluid and negotiated, proves useful in animating and authenticating boundaries by assigning historical, ideological and symbolic systems of meaning. For this reason, both the concept of boundaries and that of identity are employed in the current research, which also pays attention to class and gender differences.

\subsection{Introduction to Albanian Identity}

The national and cultural trajectories of Albania are marked by a unique and fragmented course of development, both historically and contemporarily. The factors that shaped their features appear to be bound to Albania's geographical location and, although not exclusively, to politics operating at different levels (Morgan 2002). The process of national and cultural self-definition continues today, and the two elements - the national and the ethnic - continue to be intertwined in contemporary discourse. The cliché that represents Albania as a country between the West and the East (Winnifrith 1992) has now come under attack as the country leaves behind its immediate need for economic recovery and prepares for major political projects towards the West (Kadaré 2006).

Both its timing and the 'content' of Albanian nationalism differ significantly from those of other European and Balkan countries. Albania started its attempts at national statehood several decades later than its neighbours (Lubonja 2002). Language and folk culture were at the basis of this uprising, while the process as a whole was led by intellectuals, most of whom operated from abroad (Morgan 2002). Renaissance (Rilindja) is thought to be the most significant cultural and patriotic action in the history of Albania, as it responded to the historical momentum of differentiating Albanians from the Ottoman Empire, nurturing national self-consciousness. This process was unique in that internal national unification and the task of representing claims to the outside world were merged into one (Malcolm 2002, p. 71). Borrowing from the European romanticism of the nineteenth century, it was 
based on typical myths of pride in uniqueness as a people. Thus the movement embodied a shift towards ethnic identification. 'Albanianness' was based on the link to Albania in terms of 'blood', language and culture, but not on religion, especially when the latter was associated with the Ottoman Empire (Morgan 2002).

Albanian nationalism is based on several important myths: of historical and geographical origin, of ethnic homogeneity and cultural purity, of permanent national struggle, and of indifference to religion. These myths appear both as historically informed and as important elements of identity that have been the basis of historical and political claims (Malcolm 2002, p. 73). Similarly, Albanian culture is 'an original minor culture', marked by different cultural influences due to its geographical position (Morgan 2002). Lubonja (2003, p. 3) talks about roots and layers of Albanian culture. Firstly, he points to rites and traditions based on patriarchal clan cultures enshrined in kanun, ${ }^{2}$ on top of which is positioned a long influence of Byzantine and Ottoman culture followed by the Rilindja and its influence on the diminishing importance of religion. More recently, but importantly, is the culture created and imposed by 50 years of communism, influenced also by the culture of other communist allied countries, notably Russia and China. These communist cultures also drew selectively from cultural elements of the past, by, for example, excluding religion, but retaining certain institutions, such as the family.

The broad tolerance accompanying religious openness is in effect based on a general ambivalence and fragility that characterize Albanian identity (Kadaré 2005). This fragility and ambivalence is also reflected in the choice of the main institutions of Albanian culture and nationalism. The choice of Skanderbeg as a national hero represents a strategic move from religion to ethnicity and, with Skanderbeg being a Christian, a move closer to the Western world (Lubonja 2002). ${ }^{3}$ Indeed, unlike the rest of the Balkans, religion had a minor role in the Albanian uprising against the Ottomans, while ethnicity, 'blood' and native language were more important in determining group identity (Morgan 2002). On the other hand, this loose attitude towards religion has been considered historically to be one of the main obstacles to building a strong national identity (Misha 2008). Instead, family and kin constitute the main institutions of the Albanian culture (Dingo 2007). The kin group as 'the living microcosm of Albanian society' and besa $a^{4}$ constitute two important elements of Albanian identity, especially in reaction against social and political organizations imposed from outside (Lopasic 1992, p. 104).

While, from a nationalist perspective, the three religions-Islam, Catholic and Orthodox - were seen as dividers of Albanians, communism saw them as 'opium of the people' and part of the old conservative world (Lubonja 2002; Misha 2008). It should be mentioned that matters of ethnicity and identity, and related social and political allegiances, were proscribed in Albania as in many other socialist countries in Central and Eastern Europe (Morgan 2002). Communism, in effect, constituted a

\footnotetext{
${ }^{2}$ Albanian Customary Law collected by Lekë Dukagjini in the fifteenth century. For details on the controversial and difficult interpretation of kanun in contemporary Albanian life see SchwandersSievers (1999), Tarifa (2008) and Young (2000).

${ }^{3}$ Skanderbeg signifies unity and glory as he fought against the Ottoman invasion of Albania in the fifteenth century.

${ }^{4}$ Besa means keeping the given word under any kind of conditions and being loyal.
} 
paradox in terms of its impact on Albanian identity. Being represented as a saviour from the evils of the past and a starting point for construction of a new world and new people, it retained a great deal of the nationalist mythology, since this held an important place in the collective memory of Albanians (Lubonja 2002). However, when it came to the meaning of state and nation, communism had a strongly negative effect. Communism's overall ideology paid little attention to the concepts of state and institution. Instead, it taught the Albanian people to save all their devotion and respect for the communist party (Kadaré 2005).

The new communist state, nevertheless, built much of its legitimacy on national mythology and the creation of a new homogeneous national culture as an important part of its modernizing project, with folklore its main source. There was a symbiosis of national-communist ideology with national mythology, with the 'glorious' past marked by four major moments: the Illyrian battles, the time of Skanderbeg, the Albanian renaissance and the partisan war. Its two main heroes were Skanderbeg and Enver Hoxha (Lubonja 2002, p. 95). In the meantime, communist ideology was preached as the only culture and the bearer of all truths, although its basis rested upon 'frozen moral and ideological truths', non-challengeable from the intellectual and political elite. The everyday rites and traditions of kanun and religion were radically transformed, although the clan and honour (besa) proved resistant to these changes (Lubonja 2003, p. 6). The cultural changes were also strongly associated with shifts in the communist orientation of Albania. After the break with the Soviet Union in the 1960s, the communist regime introduced a politics of isolationism. This stance supported a selective Albanian state-sponsored patriotism, with only certain elements of Albanian culture being granted legitimacy, while religion, historical consciousness and ethnic customs were controlled or completely suppressed (Morgan 2002).

More importantly, communism had an impact on identity and national belongingness. Communist ideology imposed on the people became the main instrument of repression used by the communist party, while the masses increasingly believed in a virtual reality made up of the new myths of the communist era (Lubonja 2002). On the other hand, communism's disregard for the state and its institutions gave rise to a weakening of national belongingness, as the communist state focused its devotion towards the Soviet Union as the real fatherland (Kadaré 2005). By the mid-1980s, however, ethnicity was reappearing as an important category of belongingness, while the idea of the unity of workers of the world and the idealism of achieving communism were weakening, together with the regime's legitimacy (Morgan 2002).

Nevertheless, the long period of isolation and the ensuing collapse of communism caused a major identity crisis, which was especially evident during the 1990s. With the withdrawal of the national-communist myths and symbols, Albanians lost their past and found themselves unprepared for the future in a world that was changing rapidly, whilst simultaneously discovering the distorted perception they had of themselves and their history during communism (Misha 2008). Albania's nationalist ideology was distorted more by communism than those of the other postcommunist countries in the Balkans. In the absence of a strong collective identity, 
Albanians in the 1990s returned to the fragmented social organization and action based on individual clans trying to survive (Lubonja 2002). The period of communism, like in other ex-communist countries, was seen as a historical accident (Misha 2008). Soon another myth was created: that of the West, which appeared both as a promised land, where everyone could freely choose to go and start a new life, and as a saviour, as the place where one aspires for freedom and democracy (Lubonja 2004). It also represented an element of continuity with Albania's pre-Ottoman past and an opportunity for Christianity to re-establish itself as Albanians' original faith (Lubonja 2002).

More generally, the post-communist period was characterized by a simultaneous 'chaos and crisis' in terms of moral and cultural values (Lubonja 2003). Once communism collapsed, the new Albanian state sought a balance between the continuous aspects of its history and the universal elements that inevitably were incorporated in Albania (Lako 2009). This was part of a contradiction that many ex-communist countries experienced: the demand to return to the traditional and national values abused by communism and, on the other hand, integration at a global level and reconnection with other countries and cultures. At a more micro level, the impact of communism was evident in the 'standard individual', since communism aimed to create a unique homogeneous culture. Nevertheless, the Albanian culture at the end of communism was a mixture of three main ingredients, which were incorporated in different dosages: the patriarchal and traditional, the national, and the communist (Lubonja 2003).

While the initial stage of post-communism was characterized by a 'competition' between the regimes and styles of the pre-communist era and the Western ones, together with a dose of nostalgia for communism (De Waal 2005; SchwandnerSievers 2004), there has since been a growing maturity, with discourse moving towards national identification (Frashëri 2007; Kadaré 2005, 2006). The myths of the West and of nationalism remain strong today; and there is a new awareness and confidence, not least as a result of a sense of betrayal and disillusionment that has made Albanians sceptical.

Migration is strongly related to these transformations and appears at times to be both the consequence and the cause of 'crisis' and renewed confidence. The articulated superiority of being Albanian goes hand in hand with escape from and denial of Albania for a better life elsewhere (Lubonja 2002). Misha (2008) refers to the overcrowded 'Partizani' ship ${ }^{5}$ as an important symbol of Albanians' first confrontations with the outside world, and suggests that these confrontations caused a serious crisis of self-confidence. This was part of a process of devaluation of the main social and cultural institutions, which rested on the basis of community life and in turn caused the social fragmentation which characterized Albanian society during the transition period.

\footnotetext{
${ }^{5}$ The 'Partizani' was one of the ships that Albanian migrants occupied and travelled to Italy on in 1991. It symbolically represents the migration of Albanians after the fall of communism. It is also found in secondary-school books in Italy on contemporary Europe and modern transformations of Italy.
} 
On the other hand, negative Western representations of Albania and in turn Albanian migrants' own perceptions of identity and their strategies of integration have impacted 'Albanianism at work' (Hall 1999). These representations seem to have over-emphasized the importance of kanun and simplistically explained Albanians' violence and victimhood as a 'natural' cultural predisposition. Although hiding Albanian identity was noticed also in earlier migrations (Blumi 2003), these representations are probably at the roots of Albanian migrants' mimicry and self-denial (Schwandner-Sievers 2004, p. 126).

\subsection{The First Generation}

\subsubsection{Migrant Identity}

Studies on identities of Albanian migrants are rare, and comparative studies and those on the identities of the children of migrants are almost non-existent. Studies on Albanian migration have focused mainly on the migration process, issues of regularization and integration in the labour market (see the reviews by King 2003; Vullnetari 2007).

Among various identity traits that the Albanian immigrants perceive and experience, their migrant identity is very strong and has 'blurred' distinctions based on class. ${ }^{6}$ The act of migration is now recollected with fascination but also with a more mature reflection on the historical and personal conditions at the root of the act (see also Vehbiu and Devole 2010). In general, reflections on identity were more common among migrants interviewed in Florence than in the other two sites and more common among the highly skilled or highly educated migrants. On the other hand, the search for an identity was an initial unconscious push for migrating (Mai 2002), although this is often recognized only after many years of staying abroad. The quote of Lela (female, 37, Florence) below shows how the act of migration has marked her life history, representing an undefined identity search unacknowledged at the time.

In the beginning there isn't any push... I didn't have any objectives like I am going to do this or that. I wanted to just go, that's it! I didn't come here with a plan; when I arrived in Italy I was nineteen years old with two children. I couldn't really think of any project for the future... But everyone was leaving so I thought I should try too... I wanted to go! I wasn't thinking of anything else.... I don't think people had clear ideas in those times. Albania was... I don't know how it was in those times [in the early 1990s]. A huge mess.

The first migrants encountered a sympathetic reception, both in Greece and in Italy, due to the limited knowledge of Albania apart from its history of harsh dictatorship. However, this lack of knowledge was also alienating and disempowering for the migrants, and it was then followed by a negative image of Albania and Albanians which emerged in the years to come. Some migrants' narratives indicate that their

\footnotetext{
${ }^{6}$ Migrant identity is treated for the first generation only since this was hardly relevant for the teenagers. In fact, many teenagers explicitly rejected the migrant label.
} 
migrant identity was perceived in association with the mentality and values of the socialist regime, which guided them in the settlement period and beyond. Others acknowledge the changes that they experienced, contrasting their 'new' mentality with the way of life and values they used to have under communism.

There are also differences between those arriving at the beginning of the 1990s and those arriving later, particularly after 1997, in terms of their migrant identity and the relevance of ethnicity. Due to differences in the timing of the migration to Britain compared to those to Greece and Italy, this trend also represents a general difference across the three sites. Those migrating at a later stage had different motivations, with improving their family's financial situation being a very clear goal. Those who left earlier had a different kind of migrant identity. Michelino, who left on the first ships in 1991, remembers the politicization of the act of migration and the burden of guilt and treason that the very first migrants carried. He is typical in still calling himself a refugee, a term articulated in the public discourse and which became part of the ordinary vocabulary in Albania in the early 1990s referring to all migrants.

Michelino (male, 46, Florence): What pushed me to go? What pushed the whole of Albania! If Enver [Hoxha] had been alive most probably he would have come with us! [smiles]... I thought 'I am going there, whatever happens'.

Clara (his wife, 42): Also the curiosity, for example, what is there on the other side of the sea? Because every time we were on the beach we would wonder. I was 24 , he was 28 ; we had never been out of Albania. And those years were a period of darkness for Albania.

Imaginaries and curiosity about the terrae incognitae were part of this big escape (Salazar 2011). Other migrants recollect the purpose and the outcome of migration more as cultural exchange and the desire to integrate in the 'outer' world. Taking a comparative approach towards the three subsamples, the desire to know the world and engage in an identity search is most common among Albanian immigrants in Italy, compared to those in Thessaloniki and London. This could reflect the greater knowledge of the outer world among the urban-origin migrants from western and central Albania, where most of those living in Florence come from. Migration was an adventure, a search for alternatives, fulfilment of a need for transgression for the first migrants, as opposed to the slightly more meticulous step it represented for those migrating later.

A professional identity is often strongly linked to these narratives on migrant identity, especially among those adults experiencing de-skilling and those few who managed to find a job requiring some skills related to their previous education and job experience. The majority of those experiencing de-skilling, refer to their professional identity when they evaluate their decision to migrate and discuss instances of discrimination and their children's education and job prospects.

Bardhi (male, 43, Thessaloniki): A big problem that I experienced was with the language. I couldn't... I couldn't express myself! Having been a teacher in Albania, I was used to expressing myself with a rich vocabulary, with a language that suited me, and through language you show who you are... Here you don't have a possibility to express yourself. Who you are... and then the jobs that you have to do here; you must be in very good physical, emotional and health conditions. To handle different jobs, to adapt to this society that has a job for you, that offers [only] a physical job... All these change you as a person! 
Those who found a job in the host country that to some degree matched their qualifications exhibit a strong professional identity woven in with a migrant identity and a parallel assessment of opportunity structures in both the host country and in Albania. But the 'joint' migrant and professional identity is also evident in the narratives of the low-skilled. For example, the professional identity of women in Thessaloniki is closely related to the domestic sector and the type of relationships constructed and values recognized or negotiated through this kind of work.

Furthermore, a migrant identity is associated with feelings of settlement and long-term residence in the host country. Over time, migrants change their perception of their positioning in the host society. There is a process of adaptation and acculturation that they refer to, which often involves acquiring habits and forming attitudes in accordance with those encountered in the host country. Long-term migrants also explicitly distinguish themselves from newcomers, including those from the same place of origin; and they start to make claims towards the host society and the Albanian government in terms of migrant rights and diaspora organization. This is most evident among the migrants in Greece and Italy, while in Britain this process is affected by acquisition of British citizenship and the rights and obligations associated with it. Abaz, below, is typical in attributing changes in the attitude of Greek society towards Albanian migrants to the significant progress of Albanians in terms of labour market integration.

\begin{abstract}
Abaz (male, 44, Thessaloniki): The attitude of Greek society has changed. Now it is different, it's like they got to know us; there isn't equality, but it seems like they got used to us. And it was us [that caused the change] because, to be fair, when we arrived here it was like we were freed from the chains. Not only those who escaped from the prisons, but also us that were free. I had a job in the state administration and when I came here... It was like we were freed. We experienced a huge change. Because the difference between Albania and Greece in those times was [huge].
\end{abstract}

The first generation, however, still feels economically disadvantaged after 'starting life from zero' in the respective host countries. Instead, they strive for their children to have a more secure start. On the other hand, migrant identity is also experienced and constructed in relation to labels and categorizations developed within the home country; as Hemming (2009, p. 585) puts it, migrants experience 'the status paradox of migration self-deception' during their visits home (see also Glick Schiller and Fouron 2001). Their migrant identity and apparent 'success' gives rise to the migration of others, but this 'success' is partly a self-deception because of the low-status jobs migrants perform. Meanwhile, as Lida (female, 46, Thessaloniki) points out, migrants are seen as 'lost' from the home country; a disjuncture therefore emerges:

Like it or not, one lives [belongs] where one can work, so we are twice foreigners. Firstly here in Greece we are immigrants, and also in Albania, when we go home, we are like foreigners... Things have changed in Albania, people see us as 'from Greece', as people from a foreign country because they don't know how it is [being a migrant].

Finally, the migrant identity is reinforced by the feeling of having no support from the Albanian state. Apart from a higher consciousness on the part of the migrants of receiving inefficient service from the Albanian consulates and embassies abroad, they refer to the apathy of the Albanian state and its inability to campaign for the rights of its citizens living abroad. At a deeper level, migrants express disappointment and 
a feeling of great solitude at being exposed to hardship and discrimination abroad and feeling unprotected and small because of a poor and powerless home country.

\section{Box 2.1 The identities of the first migrants: Instances of pre-modernity, masculinities and migration}

Tony is an Albanian who has a shop in the centre of Florence. He had been difficult to convince to talk to me. Today I went there and tried my luck. We soon started talking and Tony showed me pictures of two important moments of his life. The first was a picture of him doing his military service (ushtrinë). As I could recall from my own childhood, and as Tony told me, military service was an important experience for men during communism. When a man went ushtar, all of his kin would gather and celebrate like when he got married. This was an important milestone towards manhood, related to duty, hardship, separation and war. It was also the time when a man left home, in many cases for only two years of his life. It was common for men to marry and live at home with their parents. It was a period of 'crazy stuff', of independence, and a time to grow up.

The next picture portrayed Tony upon his return from his first trip to Italy. He had been on one of the boats that left Durrës in 1991 and were turned back by the Italian authorities. Tony had long hair and a bit of beard - both common features of young men who opposed the communist regime at the beginning of the 1990s. His face was grimy, as he had been travelling in bad conditions, and he was wearing a rather large cross, which Tony indicated having bought as a symbol of transgression against 'atheist' Albania during his first migration experience in 1990 in Greece, which had lasted a few weeks.

\footnotetext{
Me leaving Albania was just like when Kuqo (typical name for dogs in communist Albania) was released. He used to run away, wander around the fence... in the end he would come back to his home... We had no rights; we were denied the right to speak, to entertain ourselves, to dress as we liked, to grow our own hair! Who would have a problem because one would want to keep long hair?! I completed military service in 1986 and returned home... and those years the communist regime was close to collapsing. One of the most transgressive things I did was to go to the tailor and ask for a coat to be made; orange with blue stripes. It was fantastic; very fashionable!
}

The second picture brought back images of the early 1990s and the discontented young people who were just starting to realize how much they had been lied to. Their meeting with modernity provoked rage and, at the same time, pride at being among those who were 'gone' [emigrated].

\subsubsection{The Parental Identity}

The importance of family to the Albanians abroad is mentioned in other research (e.g., King and Mai 2008). However, among migrants of the first generation that participated in this study, references to the family and parenthood have enhanced 
meaning. Family is not only an important value but also an important structure, a 'living microcosm' to which a parent's identity is related (Lopasic 1992, p. 104). Parental identity features as the main element of identity of the first-generation parents in all three study sites. With the exception of a few highly skilled migrants for whom their professional identity was of key importance, the vast majority of the parents said that being a parent was the most important thing to them.

Mirela (female, 35, London): Being a parent is the first main thing and it never changes. The others complement each other, you can't categorize them easily; work is important, my personal advancement is important, but the security of the children and their welfare is my top priority.

Monda (female, 50, Thessaloniki): The main thing is the family, to raise the children in a good way, for them to have the most positive future. That's all. I have just left myself on the side. I have dedicated my life only to work and the children, and nothing else.

Parent and migrant identity are interwoven in the first generation and are generally experienced as the most important identity traits. Often, the family and parenthood are emphasized over ethnic labels:

\begin{abstract}
Agron (male, 42, Thessaloniki): The most important thing for me is being a worker and a parent. That's what keeps us alive, not being either Albanian or Greek. If you have a job, you work, you keep the family. These two are the most important things: work and being a parent. If you have these two you are okay.
\end{abstract}

Parental identity is also important because of the precariousness inherent in migration and living in a foreign country with no family or kin support. The lack of social integration and the difficulty of developing a career are also important reasons for the prime focus on the family and children.

Marjeta (female, 37, London): Being a mother is not bad at all [laughs]. I am very happy as a mother. I would have liked to have come here younger, so I could have progressed further, because my age doesn't allow me to go further. Now I have left this to the children.

\title{
2.3.3 Gender
}

Migration has given rise to changes in the understanding of gender among the first generation. These changes are mostly experienced by women and are reflected in their attitudes towards divisions of gender roles, based on gender inequalities and the hegemonic patriarchal understanding of family and male identity in Albania. These differences are especially stark between Albanian men and women in Florence. The impact of the host society has been significantly different for women and their partners, materializing in different trajectories of occupational mobility and at times culminating in serious tensions in their relationship, and even divorce. In turn, a rapid and silent assimilation in the host society and partnerships with Italian natives have brought other identity crises and a heightened understanding of gender relations and the need for self-empowerment. Among women in the Florence subsample, some (though only a few) chose being a woman as the main identity trait, as opposed to being a mother. In these narratives women indicated being able to articulate a sense of empowerment, independence and individuality as a result of migration. 
Lela (female, 37, Florence): Donna — a woman. And I say this because I am a free woman. If I make a good or a bad decision, it doesn't matter because if it's a good decision I have taken it myself, and if it is a bad decision it will be an experience. Saying I am a mother is still limiting. Because at the same time I am a professional, at the same time I am also proud to be Albanian... But in any case, I am a person, I am a woman and this includes everything, 360 degrees!

These women show increased agency and autonomy, expressed in a significant change of their role in the family, in their capacity to make decisions, propose and lead family projects, and in their resistance towards reproduction of 'gender roles' among their children. In Thessaloniki and London, narratives on gender are less emphasized. Immediate issues such as regularization and employment seem to take priority and blur or obstruct discussions on negotiation of gender roles. Nonetheless, as we will see in Chap. 3, different paths of integration have significantly impacted perceptions of gender in London. Nevertheless, women note changes as a result of migration in their way of dressing and expressing their 'femininity'.

Dila (female, 45, Thessaloniki): It has changed a lot [the mentality], it's different here. What can I say, the going out and these things. Because in Albania... Berat [her home town in Southern Albania] used to be very fanatical! [smiles]... [D]resses with... straps were out of the question, but even dresses without sleeves! Or short dresses, miniskirts... no.

Changes in perceptions of gender are less evident in men. Certain practices, such as involvement of men in housework and in the raising of children when the mothers are at work, are seen as normal at all three sites, at least in the case of the more educated and those originating from urban areas in Albania. In other cases, gender roles in the host country clash with persistent patriarchal ideas of male superiority in the family and excessive jealousy and control towards the wives. The case of Pali (male, 48 , Florence), below, is interesting because of his reappraisal of patriarchal values:

Here in Italy I have corrected something that has to do with the family. I had married, had finished university, had a child, but I had a mother whom I considered a saint. And I had it fixed in my mind that my mother was in the first place, and then father, then the brothers and sisters, and only then my wife. Here I came across a passage from the Bible that talked about the family. I was convinced in the meantime that I was perfectly right and I had serious conflicts with my wife. But in that case I got a good lesson from the Bible that says that when you marry, the wife has left her parents and has united with you. It is important socially that from that moment you will take a trip together and the wife is the most important person in your life.

The following section analyses in greater depth the way migration has affected the first generation's religiosity. This element within the identity of Albanian migrants is especially emphasized by the second generation, as we will see.

\subsubsection{Religious Identity}

Recent literature tends to place religion central in migration studies; the religion of immigrants in Europe is often perceived as problematic, depending on the religiosity of the native population and the historical institutionalization of religion (Foner and Alba 2008). Some scholars have shown that religion supports and is transformed by the migration experience (Levitt and Jaworsky 2007). The relation 
between migration and religiosity has its own particularities in the case of Albanian first-generation migrants. Since religion was banned in Albania, parents grew up without religion. ${ }^{7}$ At this later stage of their migration history, many comment that religiosity was instrumental in their integration and in the full integration of their children. This instrumentality is perceived differently according to the importance of religion in the host country. Monda (female, 50, Thessaloniki) described the religiosity in her family, though her husband said he was strictly an atheist:

I am baptized. I go and light [candles]... because there has remained the tradition that you need to believe in something, but not that I am a fanatic of faith. Here we became Christians; just like in every other religion it means don't steal, don't kill... I don't insist on my faith... my faith is for myself, not to give to other people... For example, my son bought a motorbike and said he wanted a panagia [a saint's icon]. 'Here it is', I gave him one. My daughter goes to the children's groups [in the church] that get together to sing, but I don't oblige her to follow that line.... I believe in God; it probably doesn't exist, but my father left this to me: that God does exist, and he told me that God is for everyone, for the Muslim, for the Roma, for the Christian.

Religiosity among first-generation migrants is understood as spirituality, as believing in certain universal values, such as respect towards humanity, doing good and helping those in need. Some parents embraced religion as part of the freedom to try ways of living and choose especially things that were prohibited in Albania, like religion. Yet others chose the 'religious route' in order to facilitate the integration of their children, who could thus participate in activities with their peers.

However, while baptism has helped social integration at a micro and meso level, and bearing a Greek-Orthodox or Catholic name has counteracted offspring's visibility as foreigners, Albanian parents had to later recognize that, as Tzanelli (2006, p. 39) points out in the case of Greece, religious conversion could not truly 'open' participation in the Greek 'nation' to outsiders. As consciousness of the (limited) opportunity structure and (closed) identity politics of the host country develops only over years, religious conversion is also referred to as an 'identity sacrifice' that generates few positive outcomes in terms of integration. In some cases reflections on religiosity are associated with feelings of resistance towards the pressure Albanian migrants experienced in the early years of immigration from the host society to get baptized and to baptize their children. At the same time, their narratives point to the role of the godparents, who are often natives related to the family as employers or neighbours, as a source of support and as important for the families in the context of their limited social integration.

\footnotetext{
Abaz (male, 44, Thessaloniki): We don't believe a lot, but now we are mixed with religion because the children are baptized. We feel ourselves Muslim, but we don't follow any rites.

Entela (female, 42, Thessaloniki): My children are baptized. I got them baptized when we came. Not that I wanted, but a Greek neighbour insisted, 'I want to baptize them! I want to baptize them...!' And the children believe in God, but it's not that they go to church and take a special interest [in religion]... like asking which [saint's] day is today or which celebration... no. But they do believe. I see them for example praying 'God, will you help me? Mum, please pray God that he helps me get a good grade.'
}

\footnotetext{
${ }^{7}$ The constitution of 1976, Article 37, prohibited religion in Albania until 1990, when the communist regime collapsed (Dingo 2007). In practice, religion had been suppressed by Enver Hoxha since the late 1960s.
} 
Fig. 2.1 'Religious corner' in an immigrant family home in Thessaloniki

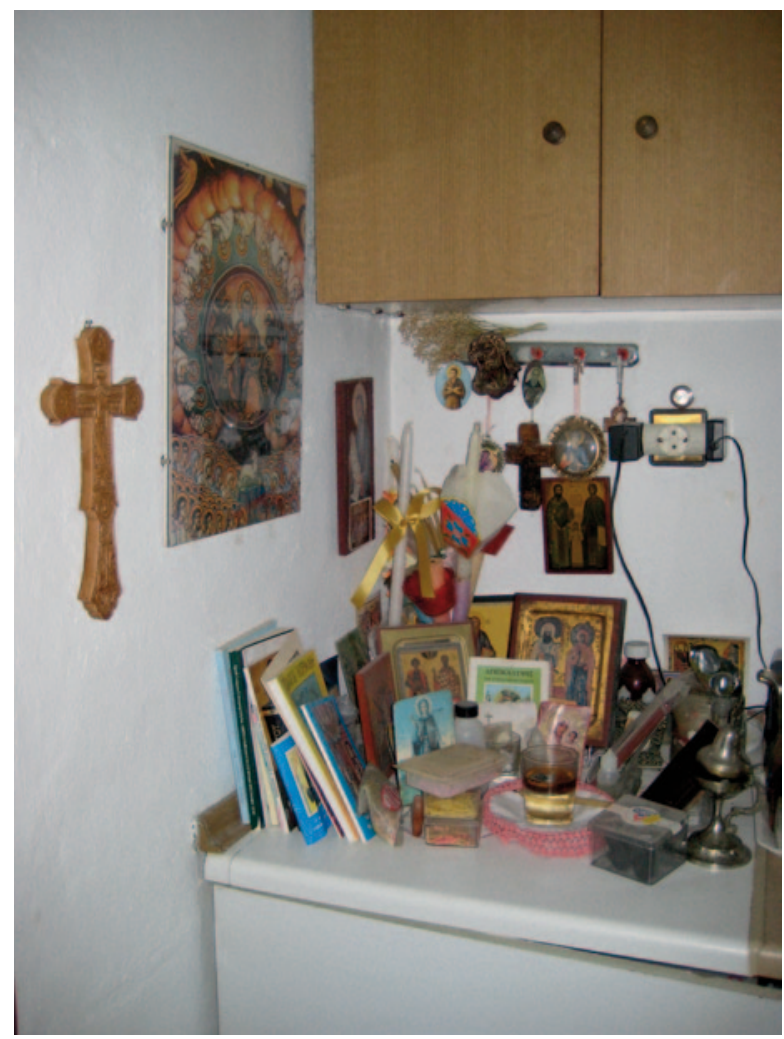

The presence of religion in migrants' lives is sometimes reflected in their household decoration, with icons, crosses and pictures of saints (Fig. 2.1). Rather different from the situation of Albanian migrants in Greece, parents in Florence are relaxed towards the religiosity of their children. Indeed, many of the adults admit to being non-religious and uninterested in religion.

There are some instances of religious conversion and baptism among the first and the second generation, but these are far less common in Florence than in the Greek context.

Dora (female, 43, Florence): My youngest son got baptized... he was praying when he was on his own secretly. He used to go to a religious school... So he used to light a candle and pray... like he was doing at school.... My son was embarrassed because none of us prayed, in our house we never talked about religion. We never mentioned it. Because as a teacher [in Albania]... I had always to mention the name of Enver Hoxha and the party in the lesson.... One day we spoke with the teacher and he said, 'Marino has decided to get baptized.' We said, 'We have no information on religion. If you think that it is the right thing to do, he can do it.' He was baptized and chose the teacher as godfather.

Religiosity in the country of residence has given many Albanian migrants of Catholic and Orthodox origin the opportunity to reconnect with their faith of origin, since the intergenerational transmission of religiosity was interrupted by communism. ${ }^{8}$

\footnotetext{
${ }^{8}$ Prior to communism, approximately $70 \%$ of Albanians were Muslim, $20 \%$ were Orthodox (mainly in the south) and 10\% were Catholic (mainly in the north).
} 
For some families from Northern Albania where the Catholic religion was prevalent, migrating to Italy has enabled them to experience a continuation in the family's religious tradition. A similar pattern was evident among Southern Albanian migrant families with Orthodox Christian backgrounds. But the link with religious continuity is not automatic. Some families of Orthodox or Catholic heritage do not pick up their religious origins once abroad.

Unlike in Florence and (especially) Thessaloniki, the first generation in London experienced no pressure to assimilate in terms of religion. The multicultural composition of the environment they live in makes religion a 'secondary' issue for their integration. Religiosity is a topic that Albanians in London relate to casually and curiously; they experience a freedom to choose their positioning.

Flutura (female, 43, London): I like being a Muslim, but here in kurbet [Albanian term for migration] you cannot follow the traditions. When we were in Albania we used to buy nice things for the children and give some money to the beggars. Here I put some money in the charity boxes during Eid or Ramadan. Or I say to my mother that she gives to the poor from the money that I send her.

There was also some mention of the traditional connection with the Muslim religion and the customs that were revived in Albania after the fall of communism. For Flutura, above, migration interrupted her 'religious' practices in Albania, which she tries to experience transnationally through her mother who lives there.

\subsubsection{The Role of Ethnicity}

Ethnic identification of the first generation appears in three main ways. First, most of the parents said they felt Albanian and identified themselves as such. Self-identification can function as a means of 'measuring' ethnic identity (Jenkins 1997; Stephan and Stephan 2000), although their self-identifying narratives may be biased. Second, some parents expressed deprecation towards Albania and the Albanian identity. Third, along with the general low importance they gave to ethnicity, some parents self-identified as being 'a good person', referring to universal human values. Symbolic ethnic identification as Albanian seems to be marked by the act of being born in Albania and having lived there most of one's life. It is uncommon for parents to question their Albanian identity; they describe their identification against a uniform host-society culture without commenting on the subgroups and diversity encountered in the environment where they live. Comments on culture and ethnicity of origin are at times marked by a 'loose' attitude towards the uniqueness and distinctiveness of the Albanian culture.

Fatmir (male, 41, London): Our culture has been mixed, five hundred years with the Turk (occupation) and then came the Greek, the Italian and the German. And it's even more mixed now because we are all over the place and we have mixed with all races.

Otherwise, the predominant attitude towards ethnicity among the long-term firstgeneration migrants appears to be part of a broader 'identity work' that has taken place alongside settlement and integration in the host country. This is most 
recognizable among highly skilled migrants, who remember this process as being associated with changes and disruptions of the identification process. Their recollections also indicate differences from parents who migrated later. The first-generation migrants who migrated to Greece and Italy in the 1990s were harshly discriminated against. In striving for acceptance, some cut their ties with Albania, changed their names, got baptized and also baptized their children. Expecting better integration for themselves and their children, some of them wholly adopted the host country's identity. Some Albanian migrants in Greece were able to register as members of the Greek minority in Albania, and encouraged their children to identify as Greek. As Valmira (female, 38, Thessaloniki) recollects below, many parents have been on a long 'identity trip':

Of course these are not the early years. I would be lying if I said that it's the same as
the early years, because many progressive steps have been made... although slow steps.
I remember when I came for the first time to Greece, I saw how small the Albanian was.
Basically how small it felt if you would say that you were Albanian. When I was hanging
around in the beginning, since I was speaking in English they were asking 'Where are
you from?' 'I am from Albania' and they would be looking at each other and I was asking
myself 'What's going on.... What is he saying with that look?' And this way I lost all the
respect that I had for myself and for Albania, for my parents, my relatives, my friends and
for everything I had experienced and had learnt in Albania. I lost it completely, I 'deleted'
it and it took a long time to understand that people are individuals who have their qualities
and those not from Albania (foreigners) are not Gods! Everyone has his own merits and
faults. It took a long time, it took a long time.

In Britain, parents faced far less pressure to hide or abandon their Albanian identity. The lines along which the Albanian community identifies were also less clear for Albanians in London due to their shorter time of residence than their counterparts in Greece and Italy. Being a small minority among many minorities and the ample space provided by the multicultural character of London make the first generation there relatively 'invisible', compared to Albanians in Greece and in Italy. As a result, those in London expressed a symbolic attachment to Albania and appreciation of both the Albanian and the host society's culture. In London, there was little evidence of the identity 'contraction' observable among parents in Greece, in particular.

In Florence, the process of acculturation and assimilation was already evident among the first generation. Although not ethnically articulated, Albanian immigrants are very receptive to Italian ways and tend to embrace practices from the context where they live. King and Mai (2009, p. 207) found that 'the key aspect of Albanian diasporic identities in Italy is the co-existence of specific conditions of vulnerability with a strong drive towards assimilation'. This is a very rational way of identifying and belonging, based on everyday life and interests and also an affinity to the Italian culture and language even before migrating to Italy (see Mai 2005). In one case, a respondent described herself and her husband as born in Albania per caso (by chance), in order to express their open-mindedness and orientation towards the West, seen through Italy, even during communism. Figure 2.2 illustrates how the Italian culture and language has 'taken over' Albanians' assimilation in Florence. Note that the invitation pictured is in Italian, as were the festivities themselves. The food served was a typical Tuscan menu. 


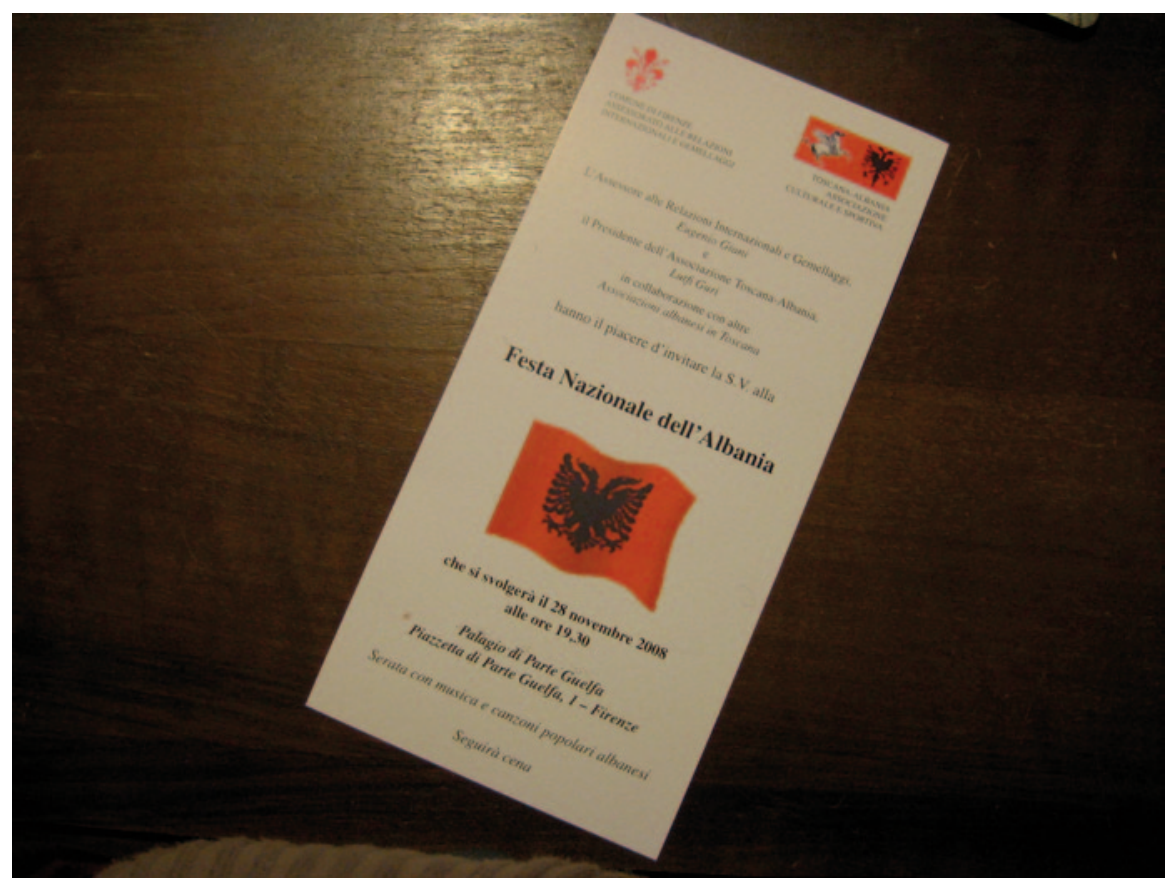

Fig. 2.2 Invitation of the Albanian community to participate in the Albanian national celebrations in Florence, November 2008. Note that the invitation is in Italian, as were the festivities themselves. The food served was a typical Tuscan menu

The first generation in Thessaloniki and Florence also shows receptiveness towards host cultures by integrating them into their family setting. This is seen in the cooking and arrangement of houses, though it is more in evidence among the highly skilled and those from urban areas in Albania. In rural-origin families, the internal arrangement of the dwelling reflects the model typical of Albanian post-communist houses, with the bufe (a cupboard with decorative cups, mugs, pictures of relatives and vases) in the central part of the room and prominent sofas against the walls (see also Dalakoglou 2010).

\subsection{The Second Generation}

\subsubsection{Teenagers and Young People}

Like first-generation migrants, teenagers, too, show multiple identities. As mentioned in Chap. 1, the literature on the identity of immigrant-origin teenagers has focused on the role of ethnicity, despite research showing that family, peer groups, schools and neighbourhood are also important referents in identity development among adolescents (Kroger 2007, p. 76). In line with these findings, multiple 
identities seemed to arise naturally among Albanian young people, although teenagers' narratives indicate that they defined themselves largely through non-ethnic identity traits. Being a teenager or young person seems to be of primary importance and what most defines them as a person.

Orjana (female, 15, Thessaloniki): At this moment, teenager. This is the one... because... Well, okay. I am a teenager, I have my own problems. Everyone thinks that I haven't grown up yet; they don't give me that much importance.

On the other hand, being a student and having hobbies, such as music and sports, and clothes and style were important to many teenagers.

Lajmir (male, 18, London): I think since my main goal is the studies,... 'student' is the most important. That's something that I do full-time; I also work, I organize events, I sing, but still that's the main thing. If I had to do only one thing, I would leave everything and would choose my studies.

Rudina (female, 18, Florence): So... [I feel like] a fashionista [smiles]. That's the closest to me and the one I care the most about. The clothes, the shoes... combine everything. I like it, I care about this.

A differentiated migration experience has also affected teenagers' identity. Differences are apparent between those who were born in Albania and those born in the host country, and between older and younger siblings. Loss of friends, harsher discrimination and more responsibility within the family make older siblings and those born abroad more mature, and the teenager identity is not as developed or casually experienced as with the younger respondents. This is also seen in the tendency of younger siblings to have more hobbies, while older siblings are more studious and pursue professions that are expected to generate a more secure financial reward. An Albanian mother in Thessaloniki describes the different emotional impact that migration has had on her two sons:

Entela (female, 42, Thessaloniki): The elder one suffered a lot. He changed environment, when he came here he didn't know the language... And still, he came here in January and started school in the third year, learnt the language and at the end of June had all his grades $10 \mathrm{~s} !^{9}$ But he closed himself off, he used to stay on his own.... Whereas the younger one came here at two years old... so he didn't really feel the transition much.

Related to the trend mentioned above, differences were observable between siblings in terms of autonomy and individuality. Those who migrated with their parents had a greater sense of responsibility. Older teenagers often assumed the role of carer and mentor to younger teenagers and at times mediated between the parents and the younger siblings, who claimed an adolescence like those of their native peers. The Albanian-origin teenagers, especially those who had migrated with their parents and even more so, those who had experienced the emigration of one of their parents and then joined the rest of the family abroad, felt they had grown up faster and earlier and were more mature than their native peers.

Children of Albanian migrants commonly experienced restrictions in the expenditures that their parents were willing or able to make on age-related activities and goods, for example, having their own mobile phone, having a bike, or going on

${ }^{9}$ Ten is the highest grade in Greek primary schools. 
school trips abroad. In many families, children shared a room. Some of them shared the responsibility for raising younger siblings as well. Furthermore, different from parents' plans for economic security and expectations for a lifestyle similar to what they were used to in Albania, teenagers aspired to have an independent life when they came of age. This is also part of their assimilation process and an expression of an individual lifestyle, as opposed to the more collective and patriarchal style in Albania.

As a result, because of the way they were growing up, their increased agency lead the Albanian-origin teenagers to draw a distinction between themselves and the natives. Lack of material goods, restricted entertainment opportunities, and parental discipline and restrictions tended to block their socialization with the native youngsters, along with conflicts in the family. An excerpt from a focus group with teenagers of Albanian origin in Tuscany explored some of these issues.

Klejdi (male, 17): I cannot really make friends with Italians. Can't quite connect with their conversations and all that.

$\ldots$

Dana (female, 15): Albanians are more mature; things are more familiar, whereas the Italians of our age are a bit...

Xhilda (female, 18): When I was little yes, I made friends with Italians; I had a l'amica del cuore (best friend). But then when you grow up you see you grow up in another way and you feel the distance.

...

Klejdi: It depends on what you like. It's not that I don't stay at all with Italians. There are boys it's a pleasure to hang out with, they know how to have a decent conversation and everything. They are not children! There are indeed Italian guys who have these qualities. But the majority I don't like as characters. It's their mentality in terms of friendship, they are not real friends, they only mind their own business.

$\ldots$

Xhilda: And then the way of entertaining. If you go out to clubs with Italians you just stare all the time, you don't know what to do. Whereas with the Albanian friends it's different, I have fun.

Klejdi: In my opinion, it's not whether they are Italians or Albanians. It depends on how people grow up, with what kind of difficulties.... Superficial boys are those who had everything when they were little, whereas boys who had difficulties have had to progress by themselves. They are more mature, more serious, they don't talk rubbish!

\subsubsection{Gender}

Gender is one of the themes that is powerfully articulated in teenagers' narrations of negotiating between home and life in the 'host' country. The gender roles that are so prevalent in post-communist Albanian society seem to have been 'transported' by the parents to the host country, although there are mothers who make an effort to counter gender divisions. Below are the perspectives of a mother and a teenager in London.

Marjeta (female, 38, London): It happens sometimes... that we respect more... well, it has remained from the old people that respect for the boys, for the brothers, is higher. But this creates conflicts with the daughter. She says, 'Why mum? Girls and boys should be equal. 
Why do you consider more the boys and you neglect the girl?' Because we are still with the old way. The boys are to be respected [laughs]. She always says, 'Why mum? He should respect me and I respect him in turn. The respect is reciprocal.' And I say, 'Firstly, because he is a brother, then he is older than you... other people wish for a brother; you have them and you don't know their value.'

ZV: Being a girl, does it affect you or will it affect you?

Era (female, 14, London): Yeah, a bit. I think it will, like you would mostly be at home doing like the ladylike work like jobs, housework, stuff like that... and if it's a boy it would be different because you would be considered as a man of the house, but yeah, because like...yeah. I just... I think it will affect me, but in small ways. If I was in another country like Albania, it would affect me more than it would here, but it still happens.... Like um... if my brother... didn't like clean his room, it wouldn't be that like much of a big deal, but if I didn't it would, because I am a girl.

As seen in the quotes above, 'traditional' gender roles are generally vigorously opposed by the girls, while in the case of the boys the attitude is mixed. Some boys expressed gendered perceptions of marriage and parenthood.

Erjol (male, 17, Florence): For example, yesterday I was with the guys of my group and there came two women that go around Tuscany and listen to young people and give advice to them. And when we were talking I was looking at her and told her ' 28 years old, with who do you live?' 'Alone' she said. 'So 28 years old you haven't married, you don't have children? You live on your own, you like your life? Sorry, but you go around like this?'

From the data it appears that the education of the parents and their origins in Albania (rural versus urban) have a major role in determining the attitudes of secondgeneration teenagers. Many parents and teenagers mentioned young friends and acquaintances who were engaged at a very early age, especially in London and Greece.

Daniela (female, 17, Thessaloniki): I have left my family now and live with the family of my fiancé. I help with cooking so that they find food ready when they come back from work tired. I do the laundry, sweep and tidy up. All these. That's why I haven't started working yet. They work and I stay at home.... This is the everyday life of a woman, the housework and all.... I have chosen this: to stay home and be a housewife, have children and do the household chores.

In the case of Daniela above, engagement at an early age, which is always to someone from the same ethnic group, living either in Albania or in the 'host' country, results in the end of age-related activities, such as taking part in sports clubs. Sometimes, it is a reason for second-generation girls to quit education. Gender divisions within the Albanian family are thus reproduced in the host country, despite many girls' acknowledging migration to Greece as an opportunity for a life that is different from those of girls in Albania.

\subsubsection{Religious Identity}

Recent studies from the USA show that religion both supports and is transformed by the migration experience (Jones-Correa 2002), while the children of immigrants are increasingly turning to 'inherited religion' as their primary source of identity 
(Chong 1998; Levitt and Jaworsky 2007). Attitudes towards religion among Albanian-origin teenagers, however, tells a different religious story. Across the three sites a number of my teenage interviewees answered positively to the question of whether they were religious, although they seldom identified religion as their primary identity marker.

At the two Southern European sites, references to religion included religiosity as a means to be accepted by their native peers, but in some cases, religion seemed to be genuinely associated with faith. As noted in the previous section of this chapter regarding the first generation, the decision to get baptized was often associated with pressure from Greek and Italian acquaintances and the host society in a broader sense. Teenagers' narratives mention the role of godparents - often natives related to the family as employers or neighbours - as a source of support and their family's limited social integration. As a result, children in Greece and Italy had largely adopted the Orthodox and Catholic religions, respectively. They were exposed to religion at school or were active in Sunday school. They attended church occasionally (though were seldom 'fanatic' about religion), while their name-days were marked by celebrations within the family. They also showed religious awareness and knowledge, which was often lacking in the parents.
$\mathrm{ZV}$ : Are you religious?
Genti (male, 18, Thessaloniki): Me... a little bit. There is no need to go to church, to pray and do other things to feel religious. The issue is do you believe or not, is faith in your heart or not. God didn't ask us to build churches and to go and pray, he never asked such a thing. God asked us to reflect and understand our mistakes and to be good people; this is my logic.
Aulona (female, 24, Florence): To tell you the truth I am not such a passionate believer. I believe in God, I pray to God and I believe in the main personages of religion... God is Jesus, the Virgin Mary... But that's all. I am not really a person that goes to church every Sunday. When I was little and we were living in Puglia, because in the small village where we were there was this tradition... so with my friends I would go to church every Sunday because there was this thing that if you didn't go... eh... whereas now that we moved here, if I go it's because I feel like going... sometimes, not always; I am not that close... I believe in God, I thank him every morning. And I have this concept that it's not absolutely neces- sary to go to church to pray to him, to thank him... Whereas my mum and dad are Muslims.

Especially in the Italian context, religious institutions and settings have been important sites for 'social time' for children and as sources of support for the parents, so they have played a significant role in integration - at least for some families. The sites and activities most often mentioned include religious education in schools, Sunday School, the church choir, Italian lessons and courses in the church, church dinners, gifts of clothes and help with accommodation. These have affected parents' and children's awareness and perception of religiosity, and somewhat increased their religious orientation. As Selim (male, 66, Florence) explains below, religiosity has also been inspired by parents' desire for their children to experience religion, which was banned in Albania.

To tell you the truth, when our daughter was little we thought we didn't want her to grow up like us. Because we lived in an era when religion was banned. So we thought our daughter should grow up with a religion, so for this reason... we decided that she became Catholic. 
In Greece, religion is often highlighted by Albanian-origin teenagers as the crucial element of cultural distinction perceived by the host society, representing a barrier to inclusion and a basis for expression of racism towards them. Baldwin-Edwards and Apostolatou (2008, p. 9) maintain that, for the greater part of the twentieth century, both the Greek state and society have exhibited a very high degree of ethnic politicization. Although the relationship between religion and ethnicity is 'intimate' (Hammond 1988, p. 3), in Greece the national ideology in Greek political culture and public discourse is based on a hegemonic form of Helleno-Christian nationalism. Religion, therefore, holds great importance in drawing political, social and cultural frontiers between 'us' and 'them' and in constituting individual and collective identities. Moreover, although religion is mostly experienced as ceremonial, Helleno-Christianism becomes very important for the natives to define themselves against the immigrants. The quote below shows this from the perspective of one of my youngest interviewees:

$\mathrm{ZV}$ : Is your family religious?

Maria (female, 12, Thessaloniki): It is, it's Christian. My parents believe in Christ, they are Christians... They believe in Easter. We baptized my sister... all of us are baptized. And I think my parents got baptized so that they could get married, because if you aren't baptized, you can't get married. They got married here.

In general, the religiosity of the teenagers represents a 'cultural discontinuity' between them and the secularity of their parents. This is especially significant in Greece, less so in Italy, and least significant in Britain. But often this generational religious discontinuity was a source of confusion for the younger generation. Here Geri describes his ambiguous feelings towards religiosity:

ZV: Are you religious?

Geri (male, 13, Thessaloniki): You mean Christian?

$\mathrm{ZV}$ : Whichever religion, I don't know...

Geri: I don't know, but my parents are Muslims. Well, me too. If my parents are, I will be, too. [smiles]... I would like to be Christian [smiles]. Also Muslim, but I would like it better to be Christian, I like it better.

ZV: Do you feel Christian?

Geri: Yes, I do, I would like to be baptized but.... We will find a godfather and then we will see whether I will get baptized, if they want [my family]... I like it better to be Christian; I don't know why, but I would like to.

Most of the teenagers in Greece and a good number in Italy had been baptized, as Christian Orthodox or Catholic respectively. By contrast, teenagers in London were freer to recognize their families' Muslim background, although, like in Albania, few families actively practised religion.

Eliana (female, 15, London): We do what they call Bajram... yeah, little Eid and big Eid, we do that sometimes because my grandparents are Muslim. And my parents are Muslim or claim to be Muslim, even though we don't go to mosque. I was about to say church! [laughs]

$\mathrm{ZV}$ : So is your family religious?

Eliana: Not really. They are not really religious. I can't really say that I am Muslim, because I eat pork, and I don't really know much about Muslim, I know more about Christianity. But right now I don't think I have a religion that I am really focused on. It is hard to keep up a Muslim religion, my grandparents were strict Muslims, had headscarves, but my parents are not that strict. 
Eliana's comments hint at the more nuanced views of religion which are possible in Britain with its pluralistic religious populations, especially in a big and diverse city like London where there are many minority-origin children of Muslim faith—something which is largely absent in Florence and Thessaloniki (or in Rome or Athens).

On the other hand, the negative connotations given to Muslims in the public discourse lead some parents and children to distance themselves from the Muslim religion and identity. ${ }^{10} \mathrm{~A}$ distancing from the Muslim religion was also evident in the articulation of religiosity among teenagers in Florence, while references to religiosity in terms of Islam are almost non-existent among the teenagers in Thessaloniki. This is similar to other research showing that the religious identity of the second generation is related to the social and historical context in which it emerges and is by no means static (Peek 2005). This leads to the final trend distilled from the interviews with the teenagers, namely that their interest in religiosity generally diminishes in late adolescence, matching the declining interest in religion of "native' youngsters as they grow older.

\subsubsection{The Role of Ethnicity}

It is by now clear that the process of identification of Albanian-origin teenagers across the three sites of this study displays a variety of trends. The strongest is teenagers distancing themselves from the Albanian identity, and this dominant trend will be analysed in due course. First, some other patterns are worthy of note. Some of the teenagers show a measure of symbolic attachment to the Albanian identity, accompanied by an interest and some knowledge about Albania and its culture. This symbolic ethnic identity (Gans 1994) is also expressed as a reaction against negative identification imposed by other teenagers in the host country, including instances of discrimination. In this case, there may be symbolic identification with Albania and Albanian identity, but the teenagers have fundamentally adopted the customs and habits of the 'host country'. This pattern is most evident among the children of migrants originating from urban areas in Albania, and among those with educated and skilled parents. They feel attached to Albanian cultural traditions, such as traditional dance, and are willing to engage in a discussion of Albanianness as 'being in their blood'.

\section{Manjola (female, 18, London): I follow Albanian tradition; my family taught me so. I am very close to my father who teaches me the Albanian tradition.... We in Britain, it seems to me, keep more the Albanian tradition than the families in Albania.}

There is also a hybrid identity being constructed (Bhabha 1994), at times not recognized or consciously acknowledged, across the three sites. Genti (male, 18, Thessaloniki) articulated this in a rather neat way: 'I feel like I have a mum from Albania and a dad from Greece; something like that.' But there are broader influences too.

\footnotetext{
${ }^{10}$ These negative connotations increased after the 7/7 events, when British citizens of immigrant descent and of Muslim religion bombed the public transport in London causing many victims. See Cole and Maisura (2007) for more on the implications of such events.
} 
Teenagers' hybrid identity draws from everyday cultural practices and a combination of the host country and home country culture, youth culture and other global cultural developments. The 'ethnic narratives' of these teenagers refer to age-related experiences, like their way of dressing, their favourite music and friendship circles, as characteristics that mark their daily 'ethnic' experience. This also resonates with Barth (1994, p. 14), who defined the cultural content of ethnicity as analytically organized in two orders: the overt signals or signs (the external features through which identity is often shown, such as dress, language, housing, and general style of life) and the basic value orientations (such as those on morality and excellence by which performance is evaluated). For both orders of Barth's typology, a distinction should be drawn between explicit self-identification and the underlying identity processes, where both overt signs and subtle signals are constructed and redefined. The primordial ethnicity - both Albanian and, especially, Greek - is referred to when a stance is taken and external categorizations are discussed or resisted. Pan-ethnic identities, European in this case, are also engaged as part of the self-identification process and 'nationalistic' avoidance, showing a relation to wider contextual issues.

Identity shifting is also very common, usually evident among teenagers who are comfortable talking about ethnic identity and those who do not experience an identificational impasse because of the stigmatization of Albanian ethnicity. Some interviewees revealed both an openness towards assimilation as a strategy to integrate (usually in Greece) and an interest in keeping their culture and not forgetting their roots (Fig. 2.3).

Anna (female, 16, Thessaloniki): I believe that we should keep this unity we have, because
living in Greece we inevitably take Greek as their culture. But we shouldn't forget our
identity, that is, we shouldn't forget our roots and who we are in reality, because this is not
good. I mean, you take others' culture and you forget your own. That's why it is good that
there are these [ethnic] organizations because they remind you of who you are and where
you are from.

Another general tendency of the teenagers is to downplay the importance of ethnic categorization. Indeed, some teenagers distanced themselves completely from this topic. Hall (1996, p. 169) maintains that 'we are all... ethnically located and our ethnic identities are crucial to our subjective sense of who we are'. Challenging this assumption, most of my teenage participants responded that they did not identify themselves in ethnic terms. ${ }^{11}$ In some instances, they did refer to human values as frames shaping their identities, such as being 'a person of all groups', being 'a good person', and so on.

ZV: Do you speak at home about Albanian culture, Greek culture? Do your parents make a distinction? Do you?

Kleo (male, 18, Thessaloniki): We don't distinguish between cultures. I am not a person that pays attention to culture. I won't distinguish between Greek, Albanian or English culture. I don't deal with this kind of thing, culture. The culture of one person is same everywhere, that of being a [good] person. That is the main culture: to be a [good] person.

\footnotetext{
${ }^{11}$ This is not to deny that Hall may be right, in the sense of ethnicity being 'assumed' and 'subconscious' and thus 'unspoken' in the interview setting.
} 


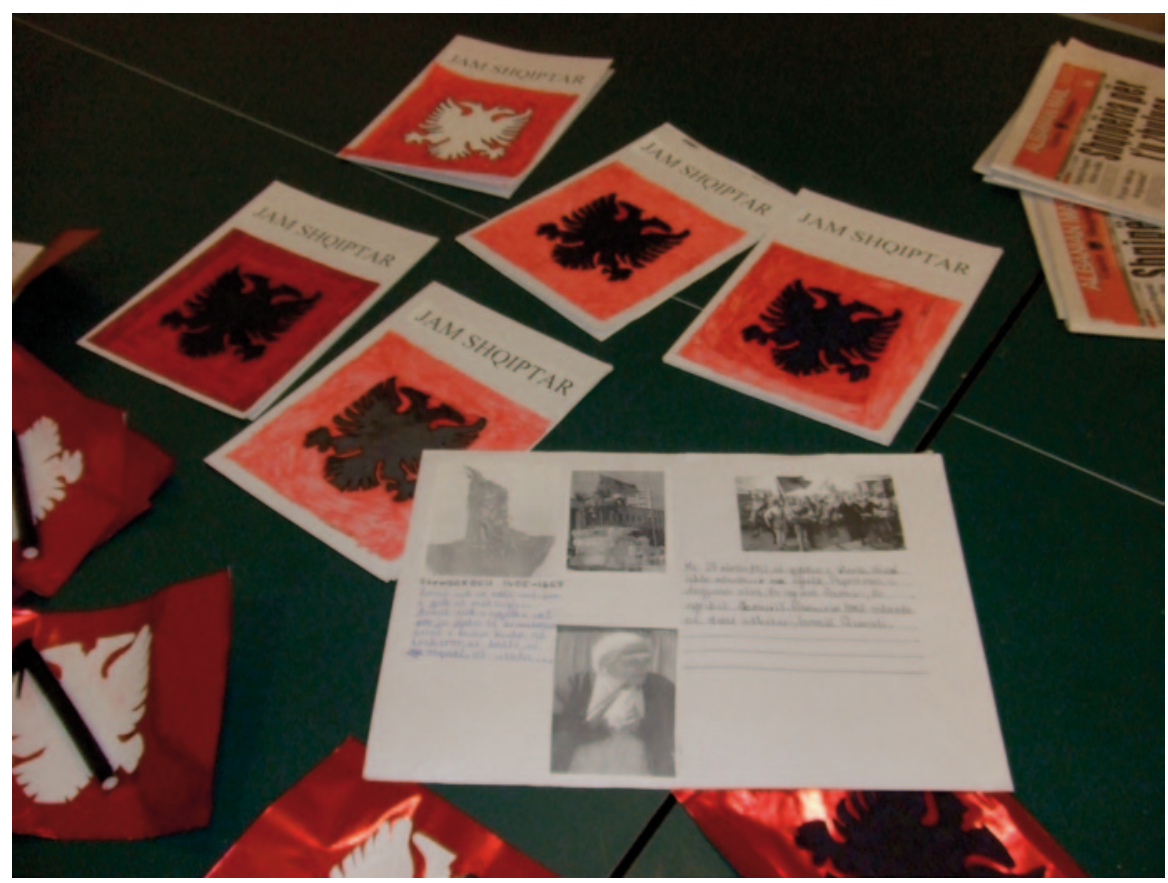

Fig. 2.3 Albanian flags and Albanian symbols painted and prepared by second-generation children in London in the Shpresa Organisation national celebrations, November 2007

Following Werbner (2010), bodily expressions and ordinary customs are seen as indicators of ethnicity; although they also express deeper, underlying understandings and experiences of individuality and autonomy versus the discipline and hierarchy advocated by parents. Nonetheless, a social orientation and tendency towards sharing as opposed to individual behaviour among teenagers is an expression of Albanianness.

ZV: You said you identify with Albanians and Albania. Why is that? Where do you see your commonalities?

Altin (male, 16, London): I mean, because this is England, so there is English people, so if there was one or two Albanians then of course you will try and be close with Albanians; you can stick together, you can fight off enemies together, you know what I mean? You can help each other, so... being Albanian, if I am Albanian and you are Albanian then we have more in common, we have hobbies in common, we have favourite food, favourite whatever.... Culture, you know... for example um... Albanians, if I buy food, if I buy chicken and chips for example, I will always, if I am with another Albanian, or even with an English person, I would always say, 'Do you want some? Take some', you know. English people, they are not really like that. If they have something, they will eat it themselves, do you know what I mean? Just small things that make a big difference, stuff like that.

Ethnic identification can be situational. The same teenager might assume any of the three main stances (Albanian, host country, hybrid) on different occasions and when discussing different topics during the interview. Darina (female, 13, London) illustrates in the following excerpt: 
I can be English, I can be Albanian, I can change like that; it's no problem for me.... I behave English when I am at school or when I have an interview with my headteacher... Yes, of course, I speak English to them. Or when I go to the job centre with my mum, for something similar... or for the British (passport) that we went and did those things... [I was] English, I spoke English without a problem. And Albanian when I am here [the premises of an Albanian association], or when I am in Albania.

Across the three sites, family, weddings and community or 'collectivity' were considered as the main markers of Albanian culture. As a result, solidarity within the family and among kin is a feature that the teenagers commonly referred to when claiming identification as Albanian. This was the case for both boys and girls. Ethnic identification can also be conditioned by the setting, such as visits to Albania and the connection that teenagers have with family and kin there. Indeed, a high appreciation of family in Albania strengthens children's propensity to feel and identify as Albanian, in contrast with the individualized life and solitude experienced in the country where they live. For some respondents, ethnic identification as an Albanian was also related to their being born in Albania and having their roots there. This was acknowledged alongside a rational belongingness to the host country because of the opportunities there and a civic responsibility towards the country of residence.

Erjola (female, 14, London): I feel Albanian mostly because my parents are from there, I know a lot of Albanian people, I have been there, I have aunties and uncles and so on.... I think I feel Albanian mostly when I go there, because here you get so used to other people from different backgrounds and so on, and you kind of forget about yours and you hear other people and it is mostly English. And when I am here I mostly feel English. When I do feel Albanian it is mostly when I am with my family, at home, my Albanian friends' house. And obviously I am Albanian.

Aldo (male, 16, Thessaloniki): I would be better described by the name Albanian because I like the name Albanian better, because it is where I was born and it will always follow me like a second name, the place I was born. I don't think I am Greek because I came to Greece. I believe that this is a place that gives me work, gives me life and that I shouldn't create problems or obstacles in this place, but I should work and make money. But the first thing for me is to have my fatherland first.

A positive appreciation of the ethnicity of the country of origin is often associated with a preference for a boyfriend, girlfriend or future partner of the same ethnic origin. Some teenagers expressing a double-identity and belongingness also indicated such a preference. Symbolic identification as an Albanian in general coexists with a rational appreciation of belongingness to the 'host' country, based on the opportunities and better living standards there. This symbolic identification was most evident among children in London. This may be related to the fact that most of the children I interviewed were recruited through Albanian organizations; the funding of Albanian organizations in London is often focused on the promotion of ethnic identity, while pressure to assimilate and discrimination are less than in Greece and Italy.

The way that teenagers in each of the three city contexts perceived the 'host' country's identity and culture is also important. There was a marked difference in the way teenagers referred to the host country's ethnic and national identity. This was articulated in strong primordial terms in Thessaloniki, with teenagers recognizing the high appreciation given in Greek public discourse to antiquity and the 'sharp edges' of Greekness. In Florence, as we will see more specifically in the 
next chapter on integration, strong references were made to the local culture and its universal values. In London, there was a perception of a fluid English culture, with a strong influence of other cultures and not holding to old or embedded traditions and conventions. Darina, Fabiola and Xhilda shed light on these differences in the extracts below.
ZV: What do you know about English culture?
Darina (female, 13, London): Um... English culture? They love football; eggs, beans, sau- sages in the morning, sit on the couch and watch TV.... [laughs] What do you want me to say? They love the pub.... That's it, because I am not interested much in the culture.
Fabiola (female, 13, Thessaloniki): I believe they had since ancient times a well-known civilisation, with Plato, but now they have degraded into whatever... Because they had this civilization, it doesn't mean that it is the same now. They 'give themselves airs' because they think it is the same now, but it is not. They speak continuously about their history, ancient times, and all that rubbish they say about the history.
Xhilda (female, 18, Florence): When I go to other cities and I tell them I live in Florence... 'Ah, Fiorentina...' I speak with a Florentine accent and they like it. 'But I have Albanian origins...', 'Ah, they say, you are Alba-Toscano... si....'. They don't call me Alba-Italian, but Alba-Toscano.

In London, Albanians' geographical dispersion and the fact that Albanian pupils constitute only very small percentages in schools means that their 'fluid' and 'light' identities as Albanians reflect a fragile identificational capacity, especially when faced by strong ethnic and religious identities performed by other minority groups in London, supported and even affirmed by the schools. Albanians have no racial distinctiveness or typical ethnic business niche, which, coupled with a 'loose' organizational and community life, leaves the children with no stable 'ethnic reference'. The very drawn-out regularization process creates uncertainty, while the stigma associated with refugee status creates a more concrete identification impasse.

Discrimination and bullying experienced at school also appear to be important reasons for hiding and rejecting Albanian identity. Yet, this outcome may also be interpreted as an attempt by these teenagers to find their own niche. Being dispersed and consisting of a small minority in a very mixed multicultural environment prompts Albanian teenagers to keep a low profile in terms of ethnic identification.

Lola (female, 39, London): In the beginning there were many young people who didn't want to admit that they were refugees, they didn't want to admit their Albanian identity. They were trying to pretend they were British, or there were cases when they were under the influence of other communities; for example, in Wood Green there are many Jamaicans and the young people... didn't have that attitude to say 'I am Albanian' and to stand up.

Contraction of identification strategies and rejection of the Albanian identity are important features of the identificational processes of the Albanian-origin teenagers in Thessaloniki. This is not to say that the symbolic ethnic identification is lacking, as can be noted from the mother-and-father quote below, but it is much less common in Thessaloniki compared to London.

Jorgo (father, 53, Thessaloniki): You can ask our daughter 'Which is the most beautiful language in the world?' She will say 'Albanian!' And which is the most beautiful country in the world? 'Albania'. 
Monda (mother, 50, Thessaloniki): Our daughter was six years old when we took her for the second time to Albania. We were on the bus, when she asked 'Are we getting close [to Albania]?' 'Yes', I told her. 'Where is our border?' And I showed her. 'Here?' she asked and she sat down and kissed the ground. All the people on the bus started laughing.

Lamont and Molnar (2002) and Wimmer (2008) see avoidance of ethnic categorization as a boundary-blurring strategy of ethnic minorities to counter racist stigmatization, while 'universalizing' human values and references to local urban lifestyle are deployed to counter perceptions of sharp ethnic divisions. However, a distinction should be drawn between the primordial and the more situational forms of ethnicity (see Kibria 2002). Both avoidance and self-identification in ethnic terms are referred to externally and primordially articulated ethnic identities, which in general are not questioned or challenged. This is not to say that a consciousness of the politics of such distinctions is missing, as Joana tells us below. However, selfidentification and the related strategies here are rational, expected to change over time and conditioned by the attitude of the host society, the economic conditions of the country of origin and the opportunities available in the future.

\footnotetext{
$\mathrm{ZV}$ : From all these qualities that we mentioned, which one characterizes you?

Joana (female, 16, Thessaloniki): That of a teenager!

$\mathrm{ZV}$ : Would you say that in another time you would choose another category as the most relevant?

Joana: Yes, I would. I would choose Albanian in future... because the more time passes, the more Albanians are liked better here in Greece, because now we still have a little bit of racism.
}

The situation is different again in Florence. The process of identification of the second-generation teenagers there is characterized by a rather 'linear' assimilation, following the same process as that evident among the parents described above, with less contraction of ethnic identification processes and an impact of locality on these processes. There are also expressions of a 'cosmopolitan ethnicity' (see Warikoo 2004, p. 383 on the ethnicity of Indo-Caribbean teenagers in New York), although the social conditions faced by second-generation Albanians in Italy are very different from the super-diverse environment of New York. Professional identity is also strong among some of the second generation who are successfully integrating into the labour market.

\footnotetext{
Aulona (female, 24, Florence): First of all, I am a designer. And then Albanian; I don’t deny it, in the end I am proud. Okay, I do feel Italian, because I have grown up here. I combine both cultures, almost fifty-fifty... and I am glad that it's like this. And when I went to France, although I stayed there very little, but seeing their culture... The more cultures I can combine, the better it is, I like it. Like the Italians say, I feel a citizen of the world, more or less.
}

The second generation also experiences a 'hierarchy' among the various despised categories of immigrants and minorities and this affects their general perception of their origin. While the negative articulation of the Albanian identity creates an identity contraction or a lack of interest in cultivating Albanian culture, the term 'extra-communitarian' (extracomunitario), as a stigmatizing umbrella term for all residents in Italy who originate from underdeveloped countries, creates another 
'identification phobia' among teenagers. These hierarchies are also observable in the attitudes of Albanian-origin teenagers towards current and future partners. Teenagers who feel integrated in Florence and identify with the national or local culture oppose a choice of partner from their own ethnic group or from other discriminated ethnic groups in Italy, such as Moroccans and Romanians. In this last aspect, they display a high degree of assimilation into mainstream (racist) Italian norms.

At all of the three sites, schools are important institutions impacting the 'content' of ethnicity for Albanian-origin children. The process of 'discovering' ethnicity is coupled with becoming conscious about the negative articulation of Albanianness in the host country's public discourse, experienced in the micro-level and meso-level institutional settings. These instances are experienced as confrontations in early years of schooling and as exclusion on the basis of ethnicity, these being harsher for children who arrive at or after school age. Stigmatization has wider connotations that include 'Albanian' as 'other', 'different', 'immigrant' and 'Muslim', contributing to a broader politicization of Albanian ethnicity. The national media and its role are prominent in 'launching' and further elaborating these connotations (see King and Mai 2002, 2008 on Italy). Although the lay jargon of 'racism' is part of the teenagers' narratives, in substance their narratives support Anthias's (1992) argument that racism is not necessarily built on explicit racial categorizations, but by using the ethnic category as a building-block it is materialized in exclusionary practices towards groups defined on the basis of racial and ethnic categories.

Blerim (male, 13, Thessaloniki): Because I was from Albania, they used to insult me. 'You are Albanian!' They used to beat me up. Everyone was against me. But after that, from the third year onwards, because I changed schools after that, some people left, some came, people changed and now they stopped. Now I am the same as the others.

In many instances an 'anti-Albanian' articulation has been internalized and further developed among the second-generation teenagers themselves. Images taken from the media and stereotypes suffered at school have created negative perceptions among teenagers towards Albanian migrants in the host country and towards Albania in general. This is evident teenagers' attitudes towards co-ethnic classmates, especially when they are newly arrived from Albania and have not yet acquired language proficiency. Intra-group exclusion is also practised towards relatives or other first-generation migrants. As most Albanian migrants have very humble jobs, children associate Albanian identity with a poor and not-so-interesting lifestyle, and with uneducated and uncivilized behaviour.

As a result, a main feature of ethnic identification strategies of Albanian-origin teenagers at the three sites consists of a distancing from their own ethnicity, striving to cross the ethnic boundary to the host society, but facing insurmountable difficulties, living thus at the edge of the boundary. Helplessness and an 'identification limbo' characterize the identification narratives of Albanian-origin teenagers, especially in the Greek context. These teenagers speak the host country's language as their main or only language, they have adopted the religion and are heading towards assimilation, but are denied a Greek identity. Changing the positioning of the boundaries is hampered by weak ethnic agency - the ability of people to change the conditions around them, especially the way they deal with their positioning within 
a society or with discrimination, by relying on the idea of belonging to a certain group of people, by the belief in a shared common past and common destiny and the assertiveness that comes with this belief. Changing the boundaries' meaning is made impossible by the resistance within Greek society and its ethnocentric Greek identity. As the account of Maria shows, this forbidden identity is experienced as alienating and disempowering.

ZV: Do you see yourself being part of an ethnic group?

Maria (female, 12, born in Greece): I don't think so. Basically I wouldn't like to be part of an ethnic group. But often this can't even happen. I can't say 'my country'... that Greece is my country, that this is the history of my country, and that this is the religion of my country... I can't say this. This would have been good, but this is not possible.... Let's say, the teacher says, 'Now we will do history'. I can't say, 'Oh, the history of my country'. Because the other children will hear and they will say, 'She went mad! This is not the history of her country. This is the history of $m y$ country'... Yes. Greece is not my country. But neither is Albania... It is not possible for Albania to be my country, because I know neither the language, nor the traditions, nor the history, nor anything from religion. I really know nothing from the history and traditions... So I constantly feel like I am somewhere at the border. I can go neither that way, nor this way!

The absence of ethnic agency disables strategies to counter stigmatization; the same absence seems to negate the creation of a reactive or adverse identity in its classic definition. This is observable among boys who employ the role of the 'reckless', asserting themselves by breaking rules, but again not referring to any collective ethnic frames. The recognition of discrimination in the case of girls shows the converse trend at times: a clear distancing from discriminative attitudes towards Greeks or any other people on the basis of ethnicity.

Lela (female, 36, Florence): In many things, my sons feel Italian. But it's enough that just a small thing... for example, when they hear something on TV or when the police stop them. Or in a nightclub when they show their identification document and, 'Ah, you are Albanian'.... Then they have this nervous reaction and they take their motorbike helmet they write ' 100 per cent Albanian' or 'skiptar'. ${ }^{12}$ This is all at a time when they feel Italian, but friends, institutions, whatever happens, tell them, 'You are Albanian; you are not like me!' And it's there where this nervous reaction comes from, when thinking, 'So I am Albanian!' but with the frustration that they are Albanian but they do not know the culture, the history and the Albanian language.

Arjana (female, 17, Thessaloniki): [I am] Albanian and a person who doesn't want to have hate for the Greeks or any other people, because that's not how I think it should be. Even if a Greek hassles me, it's not for me to react, I don't like these things; it's part of my character that I don't like to fight. I want to show that even though they are racist towards Albanians, I am cultured and this is my attitude; if you want, don't speak to me anymore.

Reading the literature on ethnicity from a 'generations perspective', one line of argumentation that emerges is that ethnic identity changes 'quantitatively and qualitatively' (Le Espiritu 1992) in different directions, over time and generations. In my sample there is a difference between the first and the second generation, and even between teenagers and their younger siblings (see also Song 1997). Most of the teenagers interviewed had younger brothers or sisters. In a few cases I was able to interview siblings, either separately or together. The older children, generally born

${ }^{12}$ Misspelling of shqiptar, which means Albanian. 
in the early 1990s, who came with or joined their parents in the first years of migration, tended to have very developed agency, as sometimes they had to take on some parenting duties. Certain features of 'migrant identity' (Waters 1994) - being selfsufficient, studying harder than the others, being more goal-oriented and achieving the main goal of their parents' migration plan ('a better future for them') - seem weaker in the younger siblings.

ZV: Do you see any differences between you and your younger sister?

Vilma (female, 16, Thessaloniki): Yes, there are differences between me and my sister because she has become just like the Greeks. She always has to ask my mum about her lessons, like 'Mum, can you have a look at this?' Greeks don't do their homework themselves; they have to ask their parents. I tell her, 'Try to do your lessons yourself; you will make a mistake, but you will learn for the next time.' She is the type that needs to ask mum. She is still very young, but it seems she is a bit insecure about what she does.

Another account is from a parent in Florence.

Lela (female, 36, Florence): When they (two sons) fight, the older one beats his chest and says 'I am Albanian!' He has this patriotism, I don't know where it comes from because he came here at five years old. And jokingly I tell him, 'But what do you know of Albania? What kind of Albanian are you?'... Or he has this protective attitude towards me because he is the man of the house... there are some things which make me think there must be something in the DNA. [smiles]

\subsection{Conclusions}

This chapter analysed the multiple identities of first-generation Albanian migrants and their children, taking a comparative and thematic approach. The findings show that there are important differences in the experience of identity between the first and the second generation. While the first generation experiences its identity mainly around roles and status, the second generation's identity is mostly focused on agerelated emotions and activities. Nevertheless, there are important in-group differences. The usual distinctions apply here in terms of different socio-economic status, education and work position among parents, which in turn affect the way children perceive and experience their identities; these aspects are comparable with those found in other research on the identification of the second generation (see Levitt and Waters 2002).

In terms of ethnic identification, however, one of the main results of this research is that the ethnicity of origin, as least in primordial terms, is not a main reference in the identification processes of the Albanian migrants and their children. Other identity traits are much more important to the teenagers; references to the primordial ethnicity are determined by contextual characteristics and factors, rather than by parents' or the ethnic community's 'legacy'. The primordial ethnicity itself is perceived as a symbolic and external entity to which Albanian-origin teenagers have to relate in their everyday lives. These findings contrast with previous studies of other second-generation groups and countries, which have established ethnicity as a core of factors influencing the identity and integration strategies of the second generation. 
There are important differences between the research sites, mainly related to the importance that ethnicity has in the public realm of each of the countries where the three cities are located. Despite these differences, among both parents and children consistent patterns of ethnic identification were found, varying from a symbolic attachment to ethnic identity to a contraction of identification and denial or avoidance of Albanian identity. As the latter constitutes a major trend among the second generation, there is little cognizance of a 'blending of cultures', which is an expectation that one would have when working with second-generation teenagers. Especially in Greece, there is a contraction of the ability to relate to any of the 'cultural sources': the Albanian one is unwanted, as it is highly stigmatized in the everyday environment, and the 'host' one is unwelcoming, with full membership and belongingness denied. This is explained by the role of actors situated in a social field in the process of boundary making (Barth 1969; Wimmer 2008). Specifically, Wimmer (2008) distinguishes between strategies that attempt to change the location of existing boundaries and those that do not aim to shift the location of a boundary, but try to modify its meaning and implication by challenging the hierarchical ordering of ethnic categories, de-emphasizing ethnicity and emphasizing other social divisions, or shifting one's own position in relation to the boundary.

Albanian second-generation teenagers generally show weak ethnic agency, though such agency is needed to implement strategies that target the location of existing boundaries or their meaning by challenging the hierarchy of ethnic categories. The boundaries are externally erected, and strategies requiring group ethnic action are not in evidence. There is some tendency towards boundary crossing and repositioning, performed at an individual level and accompanied by indifference towards co-ethnics and referring to the negatively articulated 'Albanianness' as the reference for distancing. When positioning themselves along the boundaries, external categorization and identification by others are the main frames referred to by Albanian-origin teenagers. According to Jenkins (1997, p. 61):

A claim to ethnic identity must be validated by an audience of outsiders or others- - because without such an audience the issue would not arise - but it seems to make little sense to talk about an ethnicity which does not at some point and no matter how weakly or tenuously recognize itself as such.

Discrimination appears to be an important factor shaping identification processes, a detailed analysis of which follows in the next chapter. Highlighting the difference between the primordial understanding of ethnicity and the experience of ethnicity in everyday life is important. As Kibria (2002) maintains, most of the research on the second generation has focused on primordial ethnic identity, which is indeed what is referred to by both parents and children when reactive identity or avoidance and rejection of Albanian identity are articulated and experienced. Nevertheless, ethnic identity and its transmission are understood and experienced as major factors related to Albanian migrants' and children's everyday lives, especially in relation to 'host' institutions and the public realm. The impact that this understanding has on migrants' and their descendants' perception of their identity depends on their socio-economic status and also represents gendered patterns (Anthias and YuvalDavis 1992). 
An important finding from this research is that locality impacts on identification of migrants and their descendants. As mentioned above, city identity and culture is important for the identification of these groups, especially among teenagers. This identificational trend is especially evident in Florence, where teenagers make strong references to the local culture and its universal values.

The factors affecting external identification - the 'host' institutions and the public realm and discrimination - and the role of the city are further discussed in the next chapter, which focuses on processes of integration.

Open Access This chapter is distributed under the terms of the Creative Commons Attribution Noncommercial License, which permits any noncommercial use, distribution, and reproduction in any medium, provided the original author(s) and source are credited. 